\title{
Os (des)caminhos dos cursos técnicos no Brasil
}

\author{
Michael George Costa Carneiro (UniCarioca)
}

\section{Resumo}

Neste artigo é abordado o processo pelo qual se condicionou a formação profissionalizante em seu contexto histórico, delineando vertentes de grande relevância que irão repercutir até os dias atuais, principalmente no atual momento, em que se reestruturam os cursos técnico-profissionalizantes. $\mathrm{O}$ artigo analisa também as principais ideias surgidas neste contexto de reestruturação, bem como os distintos sentidos de uma formação profissionalizante.

Palavras-chave: Formação; profissionalizante; politecnia.

\begin{abstract}
In this article the process by which vocational training in its historical context. Outlining great strands Relevance that will reverberate to the present day. Mainly in the current At which time the technical-vocational courses were restructured. The article It also analyzes the main ideas that have emerged in this context of these courses, as well as the different meanings of vocational training.
\end{abstract}

Keywords: Training; professional; various techniques.

\section{Justificativa}

Este estudo objetiva analisar os distintos sentidos para os quais apontam os cursos técnicos, através de seu desenvolvimento, estruturação e conjunto de valores. E também, com a nova realidade do séc. XXI, propor uma formulação dos cursos técnicos em defesa do valor trabalho.

As mudanças do mundo atual, principalmente na área tecnológica, interferem obrigatoriamente no mundo do trabalho. Consequentemente, no setor empresarial, surgem novas ideias, princípios, métodos, que dão sustentação a novos conceitos ligados ao grande capital. Faz-se necessário, em um movimento dialético, contrapor novos esforços em prol dos trabalhadores, no contexto do mundo globalizado.

Recentemente, toda a formação profissionalizante está sendo reestruturada pelos distintos órgãos de formação visando acompanhar as inúmeras transformações do setor produtivo. Podemos questionar: como está sendo realizada esta reestruturação? Que princípios estão norteando este processo? Que resultados este novo processo pode alimentar? Podemos traçar alguma(s) alternativa(s) ao processo que está sendo estabelecido?

Tais questões, enfrentadas e analisadas neste trabalho, são de grande relevância acadêmica, propondo-se a contribuir para o atual debate da formação técnico-profissionalizante no Brasil, no qual se inserem novos conceitos como o da especialização flexível e conceitos já consagrados na literatura pedagógica como o da "politecnia".

Assim, este trabalho torna-se bastante relevante para o meio acadêmico, porque a questão profissionalizante está, atualmente, em voga em razão do surgimento de uma nova estruturação, um novo formato, no novo contexto que se delineia no século XXI. 


\section{Metodologia}

Em um primeiro momento, procuraremos analisar as relações de trabalho no mundo contemporâneo a partir do processo de grandes transformações surgidas com a Revolução Industrial. Há as novas relações capital/trabalho, as novas formas de processamento do capitalismo, o aumento da produção industrial, etc. Tudo isso leva a uma grande transformação, não só nas relações econômicas, mas também nas relações políticas e sociais.

No contexto da Revolução Industrial, ocorre uma efervescência ideológica, surgem várias correntes de pensamento que procuram explicar as novas relações que estão surgindo. Entre elas, podemos destacar o socialismo científico desenvolvido por K. Marx e F. Engels que analisam as já citadas novas relações através da caracterização de uma dicotomia (classe dominante x classe dominada); a partir deste contexto de transformações, surgem distintas formas de processar a formação dos futuros trabalhadores. Tecnicismo, fordismo, taylorismo e toyotismo são tendências de organização do trabalho nas empresas ou linhas de produção originadas no próprio meio empresarial ou no meio acadêmico, tendo em contrapartida o pensamento das escolas politécnicas, oriundo do meio acadêmico.

No Brasil, várias instituições de ensino profissional, existentes desde o período imperial (1822/89), já mostravam uma necessidade de constituir, com apoio do poder público, formação profissionalizante, como foi o caso do Liceu de Artes e Ofícios do Rio de Janeiro. Mais tarde, já no século XX, surgem o Senai e o Senac com o intuito de qualificar a mão de obra para o segundo e terceiro setores da economia, respectivamente.

Para realização deste trabalho, requisitamos literaturas diversas, documentos oficiais, documentos do Senac, teóricos, etc., uma vez que na literatura pedagógica existe vasta obra sobre o tema, ora com tendências de formação profissional voltados aos donos do capital, ora aspirando a uma escola profissional ligada aos interesses dos trabalhadores.

Por fim, será feita a apresentação de uma possível proposta para os cursos técnicos, a partir de determinados eixos norteadores que foram identificados durante a pesquisa.

\section{Quem guarda os portões da fábrica?}

No século XVIII, na Inglaterra, começa a se caracterizar um novo modo de produção, que no séc. XIX iria se espalhar por quase toda a Europa e, no séc. XX, por quase todo o mundo. Coube a ela a primazia de realizar a Revolução Industrial.

A Inglaterra viveu o pioneirismo neste novo modo de produção por reunir determinados fatores como o intenso comércio marítimo, as grandes reservas naturais de carvão, o acúmulo de capitais, os enclousures (cercamento dos campos) e o desenvolvimento do sistema de créditos financeiros (com o Banco da Inglaterra) (Huberman, 1962, p. 192). Transformações no modo de produção modificam diretamente as relações econômicas, interferindo também nas relações sociais e políticas.

Um novo mundo estava sendo delineado, um mundo onde a energia física passava a ser substituída pela energia mecânica (máquinas a vapor), as ferramentas davam lugar às máquinas e as manufaturas às fábricas. Era espantoso naquele momento o aumento da capacidade produtiva; cada vez mais se produzia em menor escala de tempo, originando assim a produção em série - intensificando a divisão do trabalho nas fábricas (exigindo uma especificação das funções do empregado).

Nas relações sociais, a dicotomia entre a burguesia industrial e o proletariado era precisa e evidente. A burguesia industrial era a proprietária do meio de produção (indústria), do instrumental (máquinas) e do capital; o proletariado vendia sua força de trabalho em troca de um salário, consequentemente a situação de vida dos proletários assalariados contrastava com a vida de riqueza e luxo da burguesia industrial. Os proletários assalariados possuíam péssimas condições de saúde devido à falta de higiene, péssimas moradias, além de encontrar no ambiente de trabalho (fábrica), entre outros fatores, o ar em alto grau de poluição (devido às 
máquinas a vapor).

Não havia legislação trabalhista que regesse as relações de trabalho do proletariado assalariado; as regras trabalhistas eram ditadas pela burguesia industrial, conforme seus interesses.

Os proletários assalariados trabalhavam até quinze horas por dia, seis dias por semana. Não tinham direito a férias, nem seguridade previdenciária (assistência médica e aposentadoria). Pagavam-se baixos salários, frequentemente aplicavam-se aos proletários assalariados multas por atraso ou por quebra de peças. Mulheres e crianças também trabalhavam, mas recebiam salários menores. Esta exploração da classe trabalhadora possibilitou uma grande acumulação de riqueza nas mãos da burguesia; quanto menores os salários, maiores os lucros. Sendo assim,

a jornada de trabalho não é, portanto, constante, mas uma grandeza variável. É verdade que uma das suas partes é determinada pelo tempo de trabalho exigido para a contínua reprodução do próprio trabalhador, mas sua grandeza total muda com o comprimento ou a duração do mais - trabalho. A jornada de trabalho é, portanto, determinável, mas em si e para si, indeterminada. (MARX, 1996, p. 346).

É relevante relatar que além das transformações descritas, houve também, com a Revolução Industrial, um crescente processo de urbanização e progressiva decadência da sociedade rural, além de um extraordinário desenvolvimento dos meios de transporte (navio a vapor, locomotiva) e de comunicação (telégrafo).

Diante de todo esse contexto, surgiram vários pensadores e teorias para explicar as novas relações político-econômico-sociais. O liberalismo econômico procurava justificar a organização industrial com ideias como leis da natureza e a lei da oferta e da procura.

Nesse período da Revolução Industrial, devemos destacar ainda a origem do pensamento socialista e suas ramificações. O socialismo utópico, representado por Saint Simon, Fourier, Prodhon e Owen, pregava a criação de uma sociedade harmoniosa, onde os cidadãos viveriam em comunidades livres e cooperativas. O socialismo cristão, representado por Lamennais, Adolf Wagner, J. Maurice e o Papa Leão XIII, procurava apelar às classes dominantes a fim de que fossem aliviados os sofrimentos das classes dominadas.

E em meio a uma onda de protestos e agitações, em 1848 é lançado o Manifesto Comunista por Karl Marx e F. Engels. A partir daí surge o socialismo científico (principalmente após a publicação de O Capital), que possui em sua base, como forma de análise, a dialética (segundo a qual a evolução histórica das sociedades se dá por meio da superação constante das contradições) (SADER, 1986, p. 10).

O marxismo constrói seu pensamento superando ideias do pensamento hegeliano e do socialismo utópico. O marxismo terá enorme importância e repercussão em várias ciências como a economia, a ciência política e a História.

O pensamento marxista analisa uma nova concepção do processo de evolução/transformação da História; esta se processa através de uma realidade dinâmica, em que a todo e qualquer momento as estruturas estão mudando e se digladiando, transformando constante e dinamicamente as conjunturas. Daí, a abordagem marxista para a História: a dialética.

Em seu pensamento sobre as relações sociais (que têm por primazia as relações de produção), Marx analisa a divisão da sociedade em classes antagônicas: classe dominante e classe dominada. A classe dominante detém os meios de produção por meio da existência da propriedade privada. Assim Marx explica as relações de poder. Por controlar as esferas política, jurídica e ideológica da sociedade, a classe dominante permanece no poder. Já a classe dominada apenas vende sua força de trabalho.

Para o marxismo, a classe proletária não atinge sua consciência como classe (permanecendo no estágio de classe em si) devido ao capitalismo utilizar instrumentos que alienam o proletariado da realidade em que está inserido, como o feitichismo de consumo. O trabalho proletário no capitalismo torna-se alienado, o trabalhador não tem gerência sobre a produção que ele próprio realiza. Assim, Marx pergunta: 
O que estabelece porém a conexão entre os trabalhos independentes do criador de gado, do curtidor e do sapateiro? A existência de seus produtos respectivos como mercadorias. O que caracteriza, ao contrário, a divisão manufatureira do trabalho? Que o trabalhador parcial não produz mercadoria. (MARX, 1996, p. 469).

Devido à linha evolutiva de superação dos meios de produção e ao processo dialético (tese $\mathrm{x}$ antítese = síntese), Marx afirma que o capitalismo seria superado através de uma Revolução Proletária, que daria início ao sistema socialista. Para ele, distintas pessoas da categoria intelectual (os comunistas) organizariam e incentivariam o proletariado à Revolução (SADER, 1986, p. 14).

O sistema socialista teria como princípio o "desafio democrático", a busca de uma sociedade democrática, na qual os meios-de-produção pertenceriam ao Estado, e a propriedade seria coletiva.

Através da dialética, surgiria, nesta sociedade socialista, a sociedade comunista, que tem por base a extinção das classes sociais (plena igualdade) e o fim do Estado; assim a sociedade viveria uma anarquia feliz (idem, p. 49).

Nesta sociedade comunista, o processo dialético da História aparece como uma luta eterna entre o novo (vanguarda) e o velho (retaguarda), fazendo, assim, a sociedade transformar-se (eternizando o processo dialético).

Conforme está sendo demonstrado, com o processo de grandes transformações políticas, econômicas e sociais, conhecido como Revolução Industrial, a forma de trabalho sofre grandes mudanças.

No período pré-Revolução Industrial, o processo de produção era o trabalho artesanal, no qual o artesão produzia em sua oficina e com suas ferramentas os produtos a serem reapropriados por terceiros. Não havia uma produção em larga escala (como após a Revolução Industrial), porém produzia-se a quantidade encomendada ao artesão. O artesão, além de trabalhar de forma relativamente autônoma, sem produção de larga escala, vivia do valor arrecadado de suas vendas e produzia seu produto por inteiro.

A partir da Revolução Industrial, a forma de trabalho conhecida como artesanal vai se diluindo e perdendo a importância no sistema econômico de produção.

Assim, com a Revolução Industrial, surge o trabalho proletário no ambiente das fábricas. Nesse momento, o trabalhador perde seu sentido de autonomia (independência), passa a ser um empregado de uma determinada indústria, seguindo as determinações da direção dela. O proletário recebe um salário como forma de contraprestação da força de trabalho empregada por ele e, diferentemente do artesão que fazia todo o produto, realiza apenas uma parte da produção. É o chamado trabalho em série, impulsionando assim a produção em larga escala característica do setor industrial. Assim:

\begin{abstract}
um trabalhador o qual executa a sua vida inteira um única operação simples, transforma todo o seu corpo em órgão automático unilateral dessa operação e portanto necessita para ela menos tempo que o artífice, que executa alternadamente toda uma série de operações. O trabalhador coletivo combinado, que constitui o mecanismo vivo da manufatura, compõe-se porém apenas de tais trabalhadores parciais unilaterais. Em comparação com o ofício autônomo produz por isso mais em menos tempo ou eleva a força produtiva do trabalho. (MARX, 1996, p. 455/456)
\end{abstract}

É importante relatar que o proletário trabalha (produz) para a burguesia industrial; o resultado de seu trabalho não lhe pertence, é apropriado pela burguesia. Consequentemente, o proletário se aliena em sua produção de trabalho, produz aquilo que não será seu; daí seu trabalho perde o sentido de libertação e o escraviza na rotina, na má remuneração, na estagnação profissional. O proletário deixa de ser um trabalhador e passa a ser um empregado.

Deve-se entender, para efeito de pesquisa, emprego como cargo ou ocupação de um determinado serviço e trabalho como a aplicação das forças e faculdades humanas de maneira consciente para alcançar um determinado fim (Braverman, 1977, p. 45). Temos caracterizada, assim, a distinção das duas formas de realização produtiva (trabalho x emprego) pós-Revolução Industrial. O emprego possui um carácter alienado, o empregado apenas preenche um cargo ou ocupação na realização de determinada(s) tarefa(s), é algo que pode 
ser facilmente substituído; é apenas mais uma peça no sistema e, como peça, é usado enquanto é eficiente para a máquina. Quando cai em desuso ou é ineficiente, é abolido.

Já o trabalho é a realização produtiva de um determinado objeto por meio da utilização das forças e/ou faculdades humanas conscientemente. O trabalhador utiliza-se da sua consciência na realização de seu trabalho, age através de um senso crítico-reflexivo, não deixando o resultado de seu trabalho alienar-se de si.

No trabalho, articulam-se teoria e prática como momentos inseparáveis e dialeticamente relacionados, do processo de construção do conhecimento e de transformação da realidade (KUENZER, 1989, p. 184).

As duas sentenças acima se aproximam de determinados princípios marxistas, o trabalho-mercadoria e o valor-trabalho.

O trabalho-mercadoria é aquele em que o profissional vende sua força de trabalho como se fosse uma mercadoria. Em um sistema capitalista, o profissional vende esta força de trabalho ou consegue ter uma melhor remuneração de acordo com as leis de mercado (lei da oferta e da procura) e não através de negociações, através da dialética da luta de classes. É um profissional que se aliena daquilo que faz em seu emprego, porque não o faz para si; nem a forma como o faz foi determinada por si próprio ou teve sua participação. Parte-se do princípio de que

o trabalho, na sociedade industrial capitalista, se transformou em mercadoria, como consequência, o homem voltaria a ser livre quando fosse dono de seu trabalho, quando retornassem a suas mãos seus próprios instrumentos de trabalho, enfim, quando controlasse o que produz e para que produz. (GOMEZ, 1989, p. 48/49).

O valor-trabalho é aquele em que o profissional possui participação ativa na realização de seu trabalho; ele faz sentir o valor de seu trabalho. É um profissional que participa ativamente na constituição de seu trabalho, não apenas como forma de realização de tarefas, mas como membro-ativo no processo de tomada de decisões. Assim:

enquanto relação social, a partir da qual se compreende não só como se produz dentro da relação capitalista o conjunto das relações sociais, mas como se produz historicamente a própria relação capitalista. (FRIGOTTO, 1989, p. 20/21)

Assim sendo, no mundo contemporâneo podemos caracterizar as distintas formas descritas acima no sentido educacional que se dá aos cursos de formação técnica profissionalizante.

Há cursos profissionalizantes no sentido de formar empregados aptos aos comandos da burguesia. Esta educação para o emprego é algo muito realizado em treinamentos nas próprias fábricas e/ou em instituições educacionais controladas ou dominadas pela burguesia. Criam-se cursos a partir de objetivos e metas preestabelecidas pelo mercado de trabalho, gerando, assim, empregados conformados com a sua realidade, seguidores dos comandos de outros e transformados em peças de reposição. Assim,

na medida em que, para dominar, se esforçam por deter a ânsia de busca, a inquietação, o poder de criar, que caracterizam a vida, os opressores matam a vida. Daí que vão se apropriando cada vez mais, da ciência também, como instrumento para suas finalidades. Da tecnologia, que usam como força indiscutível de manutenção da "ordem" opressora, com a qual manipulam e esmagam. Os oprimidos como objetos, como quase "coisas", não têm finalidades. As suas, são as finalidades que lhes prescrevem os opressores." (FREIRE, 1993, p.47)

Contudo, há também a possibilidade de formação de trabalhadores em um sentido mais amplo, em um sentido libertador. A educação para o trabalho objetiva despertar nos futuros trabalhadores o senso crítico-reflexivo de sua realidade, inclusive no meio de trabalho. Deseja-se formar trabalhadores que não sejam apenas uma espécie de mecanismos para se chegar a um determinado fim, que não é moldado com a participação dos trabalhadores. Deverão ser formados trabalhadores críticos, construtores da realidade que os cerca, efetivos participantes na constituição do processo, dos meios e fins a serem alcançados no ambiente de trabalho, que tenham consciência para debater e atuar na constituição da relação capital/trabalho. 
Esta perspectiva pode ser sintetizada pelo princípio da politecnia, tema já apontado por Marx e Engels em Textos sobre Educação e Ensino (1983), posteriormente também analisado por Lênin em Sobre a educação (1977), por Kurpskaia em Sobre a educação comunista (s/d) e por Gramsci na obra Os intelectuais e a organização da cultura (1968).

\section{Um museu de grandes novidades}

Atualmente, devido a inúmeros fatores (como desemprego, inadequação entre o curso e realidade profissional, etc.), ocorrem intensos debates de como profissionalizar trabalhadores em um mundo globalizado? Um mundo de grandes transformações, como supercompetição, redução da atuação do Estado como empregador (proposta neoliberal), fusões de grandes corporações, desemprego crescente, etc.

Diante de tal contexto, surgem novas vertentes quanto à formação profissionalizante, que, na realidade, procuram adequar os interesses dominantes à conjuntura do mundo atual. Entre elas, podemos citar:

Especialização flexível - no Brasil este tipo de curso possui a nomenclatura de curso básico de qualificação, de acordo com o Decreto no 2208/97 (este Decreto regulamenta a educação técnico-profissionalizante no Brasil). Criam-se, assim, cursos de caráter específico, conforme determinada necessidade do mercado de trabalho privado, com caráter empregatício (necessidade urgente de mão-de-obra qualificada em determinado ramo), setorizado (para atuar em um setor específico do mercado) e temporal, ou seja, o curso funciona enquanto o mercado estiver absorvendo a mão-de-obra que está sendo qualificada; quando não estiver mais absorvendo, ele é encerrado. Vale destacar que, por isso, estes cursos têm um caráter de especificação (próprio de uma determinada espécie) e não de especialização (tornar-se especial). Fica a questão: o que será dos trabalhadores que realizarem este tipo de curso após uma mudança na realidade de seu trabalho? Serão "expulsos" do mercado de trabalho?

Polivalência - Deseja-se que, ao findar um curso profissionalizante, o futuro profissional possua um desempenho qualificado em várias tarefas dentro de uma mesma função. Deseja-se criar uma funcionalidade multifacetada para eles em seu ramo empregatício. Por exemplo: atualmente, no Curso Técnico de Formação em Contabilidade no Senac/RJ, os futuros técnicos em Contabilidade, ao completarem o terceiro módulo do curso, concluem compulsoriamente o curso de auxiliar administrativo. Podemos supor que, quando uma determinada empresa precisar de DOIS profissionais distintos (auxiliar administrativo e técnico em contabilidade), contratará apenas um (formado pelo Senac/RJ), desempenhando o papel de dois, recebendo UMA remuneração. Segundo Marx (1996, p. 477), a isto se dá o nome de mais-valia. Poderíamos chamar esse tipo de curso profissionalizante de curso funcionalizante (que faz você funcionar na engrenagem do mercado).

Desenho Curricular / Módulos - de acordo com as necessidades do mercado de trabalho, desenha-se um currículo que dará sustentabilidade funcional aos cursos. Antes havia uma grade (estava-se preso) agora há um desenho curricular, calcado no que o mercado determina. O desenho curricular proposto pelo Senac terá sua funcionalidade garantida em um sistema modular. Agrupam-se várias áreas de conhecimento afins e forma-se um módulo que vai sendo superado gradualmente pelos educandos de forma individual. Caso ocorra reprovação, o educando terá que refazer apenas o módulo. Caso queira se requalificar/atualizar, fazse apenas o módulo desejado. Todavia, as instituições que oferecem este tipo de currículo o oferecem de forma linear (primeiro o módulo 1, depois o 2, etc.). Fica a questão: caso um trabalhador queira se requalificar, em carácter de urgência, como ele o fará, se o módulo desejado não está sendo oferecido naquele momento?

Profissional com vida útil - formam-se profissionais enquadrados às necessidades do mercado de trabalho. São voltados para o sentido do trabalho-mercadoria, só que agora esses profissionais além de realizadores de tarefas e funções, alienados, vendedores da força de trabalho, terão também uma vida útil. A vida útil deles durará enquanto o que eles aprenderam tiver confluência no mercado de trabalho. Quem sabe, futuramente, ouviremos "ou um profissional que saiu de uso em 2020... Se o profissional for submetido exclusivamente ao processo pedagógico desenvolvido no interior da fábrica, o operário dificilmente terá acesso aos instrumentos teórico-metodológicos e ao saber socialmente construído que lhe permita compreender as relações sociais das quais 
faz parte e superar sua situação de classe. (KUENZER, 1989, p. 189)

\section{É preciso acreditar em um novo dia, na nossa grande geração perdida}

No contexto que estamos discutindo, argumentamos a favor de cursos profissionalizantes no sentido valortrabalho. Cursos que objetivem contribuir para o trabalhador sentir o valor de seu trabalho, participar ativamente no processo produtivo, não apenas como um realizador de tarefas, mas como um agente participativo da constituição de seu trabalho. Um agente útil a si mesmo e à sociedade em que está inserido. Concordamos com Gomez (1989), quando afirma que

a única via para ultrapassar as diversas manifestações de alienação será a transformação radical da sociedade. Essa mudança radical, essa emancipação, se dará no momento em que se criem as condições favoráveis para que o conjunto dos trabalhadores, dos produtores, assumam a direção da produção, 0 que implicitamente representa tomar a direção da sociedade. (GOMEZ, 1989, p. 53)

Cursos que deem valor à cidadania (à formação do cidadão crítico) incluem um processo educacional amplo, que não fique apenas na esfera do saber fazer.

Contempla o saber fazer, mas também o saber ser e a construção de conhecimento (saber saber), aspirando formar um trabalhador cidadão - que não tenha um comportamento meramente reprodutivista - que seja um agente participativo-transformador não só em seu ambiente de trabalho, mas na sociedade como um todo. A educação profissional

poderia desempenhar, nesta trajetória, papel relevante, desde que seja coerente com a formação de um sujeito capaz de História própria e mais humana, não apenas mais produtiva. (DEMO, 1998, p.3)

Os cursos devem ser constituídos a partir de características, competências, objetivos extraídos do Mundo do Trabalho (e não apenas do mercado de trabalho), com a participação de distintos setores deste Mundo. O conflito de ideias nesse processo contribui para que de uma forma dialética surja a síntese que irá dar sustentabilidade funcional para a constituição dos cursos. Assim sendo,

eleger o mundo do trabalho como ponto de partida para a proposta pedagógica da escola comprometida com os interesses dos trabalhadores não significa propor uma formação profissional estreita e limitada, determinada pelo mero "saber fazer" despido de compreensão, de análise, de crítica. (KUENZER, 1989, p. 191)

Seria ingênuo acreditar que o mercado de trabalho privado não vá participar (direta ou indiretamente) do processo de constituição dos cursos, porém este não deve ser o único ator a ser ouvido neste contexto. É relevante destacar que os cursos devem ter um outro sentido filosófico (de valores) em sua constituição.

É fundamental que a escola sirva à população de uma forma geral, que supere os limites da dimensão técnica, ampliando-se a uma dimensão política, formadora de trabalhadores.

Defendemos a politecnia como base para os cursos técnicos. Pretende-se formar o técnico em uma visão de valor-trabalho, para que ele, além de adquirir habilidades pertinentes a sua profissão, desenvolva também um caráter crítico-reflexivo na realidade social em que esteja inserido.

Assim, é possível a qualificação de trabalhadores transformadores da realidade, não só da fábrica, mas também de toda a sociedade. Formar agentes sociais participativos, que construam, conscientemente, em prol de si próprios e da sociedade como um todo.

A politecnia é uma escola que aspira ao desenvolvimento pleno dos educandos, ou seja, uma educação integral. Em uma escola técnico-profissionalizante, por exemplo, a politecnia se processa através da união da educação intelectual com a educação tecnológica. Uma escola na qual o processo ensino/aprendizagem não se restrinja apenas à absorção de técnicas, mas em que haja também a aprendizagem das técnicas simultaneamente com uma compreensão mais ampla da realidade. Na escola politécnica, 
não é suficiente apenas um domínio das técnicas: faz-se necessário dominá-las a um nível intelectual. Além da iniciação no manejo das ferramentas básicas utilizadas nas diversas atividades de trabalho, é fundamental permitir à criança e ao jovem o acesso aos conhecimentos necessários à compreensão científica do objeto em estudo, seja ele uma máquina, um fenômeno da natureza ou uma relação socialmente produzida. (MACHADO, 1991, p. 129)

Nesse sentido, a busca por colocar o homem em sintonia com o processo de transformação da realidade é inerente à escola politécnica. A partir do momento em que esta escola almeja a compreensão da realidade ampla, vivida pelo homem, o processo de crítica-reflexiva é de grande relevância. Somente através da crítica-reflexiva, o homem terá capacidade de análise, compreensão e (re)construção da realidade. Terá capacidade, por exemplo, de compreender (e, quiçá, interferir) na relação de continuidade-ruptura do processo histórico.

Daí, a escola politécnica torna-se um fomento de transformação, no qual os educandos têm, como instrumento principal de compreensão da realidade, a dialética. Assim, instrumentaliza os trabalhadores a assumirem o comando da transformação social.

A politecnia deseja formar cidadãos crítico-reflexivos, que possuam atitudes autônomas e que tenham compreensão sobre o mundo do trabalho. Ela deseja fomentar a síntese

dialética entre formação geral, formação profissional e formação política, promovendo o espírito crítico no sentido de uma qualificação individual e do desenvolvimento autônomo e integral dos sujeitos como indivíduos e atores sociais, possibilitando não só sua inserção mas a compreensão e o questionamento do mundo tecnológico e do mundo sociocultural que os circundam. (DELUIZ, 1996, p. 120)

Este tipo de formação se fará sentir à medida que, além da aprendizagem das habilidades técnicas (que são também de grande importância), a formação seja mais ampla, perpassando por princípios como a produção de conhecimento e o despertar do senso crítico-reflexivo. Esta formação mais ampla tem como centro não a servidão ao capital, mas aos ideais humanos.

\section{Conclusão}

Analisamos neste trabalho distintas formas/modelos de qualificação dos trabalhadores. Distintas formas/ modelos de realização de cursos podem ser pensados e executados, porém em um sistema capitalista podemos dizer que existem apenas dois sentidos que se podem dar aos cursos profissionalizantes: formar o profissional para ser um trabalhador (valor-trabalho) ou formá-lo para ser um empregado (trabalho-mercadoria).

A formação profissional gera um empregado, se, no desenvolvimento do curso, o futuro profissional tiver sua formação voltada única e exclusivamente para a aprendizagem de técnicas e habilidades, em que não haja praticamente nenhuma preocupação com o processo de produção do conhecimento, restrito a uma reprodução de informações/comportamento. Assim sendo, será estimulada a formação de profissionais aptos possivelmente apenas para realização de tarefas, profissionais que provavelmente saibam fazer com eficiência as funções operacionais de seu ramo profissional, alimentando uma formação estreita.

Em outro sentido se faz presente também a profissionalização que poderá formar trabalhadores. Este tipo de formação se fará sentir à medida que, além da aprendizagem das habilidades técnicas (que são de grande importância), o curso seja mais amplo, perpassado por princípios como a produção de conhecimentos e o despertar do senso crítico-reflexivo. Busca-se além de uma formação para o trabalho em si, uma formação que alie o conhecimento técnico ao conhecimento humanístico - que dê valor não só à formação do técnico-profissional, mas à formação do ser humano como um todo. 
Assim, quanto à formação dos trabalhadores, defendemos que ela esteja de acordo com as necessidades do mundo do trabalho, em que as três esferas que compõem as competências (saber fazer, saber ser e saber saber) sejam debatidas e constituídas pelos vários atores e interesses distintos que compõem o mundo do trabalho. Deve-se formar um amplo fórum de debates entre estes distintos segmentos do mundo do trabalho, resgatando, periodicamente, as transformações deste "mundo" para estabelecer as competências a serem desenvolvidas nos distintos ramos e cursos técnicos. Ao mesmo tempo, cursos e profissões devem estar inseridos em um contexto de educação continuada, para tentar garantir a permanência dos trabalhadores ativos no mercado de trabalho (que só se tornará efetiva em períodos de crescimento ou desenvolvimento econômico). Tais cursos devem ser realizados não só por aqueles que estão entrando no mercado, mas também pelos que já estão trabalhando a título de aprimoramento ou requalificação. Procura-se evitar, assim, que os profissionais tenham uma vida útil para o mercado de trabalho.

Defendemos uma formação profissional que esteja preocupada em formar trabalhadores crítico-reflexivos, transformadores da (ampla) realidade social na qual estão inseridos. Assim podemos afirmar que o sentido mais adequado para se processarem os cursos técnicos é o do valor trabalho, oferecido pelo princípio da politecnia.

Todavia, ela deve ser implantada pelo Estado brasileiro no sentido de termos uma formação técnico-profissional focada na constituição do ser humano enquanto pessoa, enquanto cidadão e enquanto profissional, e não reduzir a formação apenas a apelos mercadológicos momentâneos de instituições que ora regulam o mercado de trabalho.

Somos humanos e não uma simples peça na engrenagem para o sistema.

\section{Contato do autor}

Michael George Costa Carneiro | m.g.carneiro@hotmail.com

\section{Referências Bibliográficas}

BRAVERMAN, B. O Aprendizado e o Treinamento na Indústria. São Paulo: Atlas, 1987.

DELUIZ, N. As mudanças no mundo do trabalho e no mundo vivido: consequências para uma nova relação entre educação geral e formação profissional numa perspectiva de politecnia. In: MARKERT, W. Trabalho, qualificação e politecnia. São Paulo: Papirus, 1996.

DEMO, P. Educação profissional: vida produtiva e cidadania. In: Boletim técnico do senac. Rio de Janeiro, v. 24, n. 1, jan./abr., 1998. FREIRE, P. Pedagogia do Oprimido. Rio de Janeiro: Paz e Terra, 1987.

GOMEZ, C.; FRIGOTTO, G.; ARRUDA, M.; et al. Trabalho e Conhecimento: dilemas na educação do trabalhador. São Paulo: Cortez/Autores Associados, 1989.

GRAMSCI, A. Os intelectuais e a organização da cultura. Rio de Janeiro: Civilização Brasileira, 1968.

HUBERMAN, L. História da Riqueza do Homem. Rio de Janeiro: Zahar, 1962.

KRUPUSKAIA, N. Sobre a educação comunista. Moscou: Ed. em Línguas Estrangeiras, s/d, 1986.

KUENZER, A. Pedagogia da fábrica: as relações de produção e a educação do trabalhador. São Paulo: Cortez/Autores Associados, 1989.

LÊNIN, V. Sobre a educação. Lisboa: Seara Nova, 1977.

MACHADO, L. Politecnia, escola unitária e trabalho. São Paulo: Cortez/Autores Associados, 1991.

MARX, K. O Capital. São Paulo: Nova Cultural, 1996.

; ENGELS, F. Textos sobre educação e ensino. São Paulo: Moraes, 1983.

PLANALTO EDITORIAL. Enciclopédia de Biografias. Nova Friburgo: Planalto Ed., 1984.

SADER, E. Marxismo e teoria da revolução proletária. São Paulo: Ática, 1986. 